\title{
Sistem Pendingin Ikan Tenaga Surya Berbasis Mikrokontroler ATMEGA328
}

\author{
Muhammad Yasin ${ }^{1,}$ Herlinawati $^{2}$, Syaiful Alam ${ }^{3}$ \\ Jurusan Teknik Elektro Universitas Lampung, Bandar Lampung \\ Jl. Prof. Sumantri Brojonegoro No.1 Bandar Lampung 35145 \\ 'arf.yasinegmail.com \\ herlinawatideng.unila.ac.id \\ syaiful.alam@eng.unila.ac.id
}

Intisari - Salah satu permasalahan yang sering dihadapi oleh nelayan adalah mengenai penanganan pasca penangkapan. Nelayan mengharapkan ikan yang ditangkap tetap segar sampai di tangan konsumen, sehingga dapat dijual dengan harga jual yang tinggi, tetapi fakta yang ada saat ini ikan hasil tangkapan sering mengalami perubahan baik secara fisik maupun kimia yang kemudian secara bertahap mengarah pada proses pembusukan sehingga mengakibatkan harga jual ikan menjadi berkurang. Tujuan dari penelitian ini adalah untuk merangcang sebuah pendingin ikan tenaga surya yang dapat mempertahankan suhu dengan jangka suhu $0-5^{\circ} \mathrm{C}$ dan dapat diimplementasikan langsung di nelayan sehingga diharapkan dapat membantu nelayan dalam penanganan ikan pasca penangkapan. Alat ini mempunyai mempunyai kapasitas $35 \mathrm{Kg}$ ikan. Pengujian alat ini dilakukan di desa Pulau Pasaran, Bandar lampung. Pengujian dilakukan selama 3 jam. Dari hasil pengujian didapatkan alat pendigin dapat mempertahankan suhu $0-5^{\circ} \mathrm{C}$ sesuai dengan standar. dan berdasarkan perhitungan alat ini dapat hidup selama 7,9 jam.

\section{Kata Kunci : Nelayan, Ikan, Pendingin, Panel Surya}

Abstract - One of the problems frequently faced by fisherman is about post-catched fish handling. Fishermen expect to have fresh fishes delivered for consumers in the market places to get high selling price when they are sold. However, the current fact is that the fishes are commonly found to be physically and chemically changed and then gradually, the quality is going low due to the loss of preservation which causes the selling price of the fishes decreases. This research aims to design a solar powered fish chiller system that can maintain the temperature in a range of $0^{\circ} \mathrm{C}$ until $5^{\circ} \mathrm{C}$ and be able to be implemented for fisherman directly, so that can help them in handling fish after catching. The instrument has a capacity in the amount of 35 kilograms fish. It is tested in a village of Pasaran Island, Bandar Lampung. The testing periode that was carried out is 3 hours. The analysis of the data concludes the chiller system can maintain the standard temperature between $0^{\circ} \mathrm{C}$ and $5^{\circ} \mathrm{C}$ and exxtrapolation of the analysis states that the system can be active in 7,9 hours.

Keywords : Fisherman, fish, chiller, solar panel

\section{PENDAHULUAN}

Indonesia secara geografis merupakan negara dengan dua pertiga luas lautan yang lebih besar daripada daratan. Hal ini bisa terlihat dengan adanya garis pantai diseluruh Indonesia yang mencapai $95.181 \mathrm{~km}$ (World Resource Institude, 1998) dengan luas laut
5,4 juta $\mathrm{km}^{2}$ mendominasi luas teritorial Indonesia sebesar 7,1 juta $\mathrm{km}^{2}$. Potensi tersebut menempatkan Indonesia sebagai negara yang dikaruniai sumber daya kelautan yang besar termasuk keanekaragaman hayati dan non hayati dengan wilayah perikanan tangkap di perairan seluas 54 juta hektar dengan potensi produksi 0,9 juta ton/tahun, besar potensi hasil laut dan perikanan 
mencapai 3000 triliun/tahun, akan tetapi yang sudah dapat dimanfaatkan hanya sekitar 225 triliun/tahun atau sekitar 7,5\% saja. Food And Agricalture Organization di 2012 menyatakan bahwa Indonesia menempati urutan ketiga dalam produksi perikanan terbesar didunia. Luasnya laut di Indonesia membuat sebagian besar penduduk sekitar pantai memilih untuk berprofesi sebagai nelayan. Salah satu permasalahan yang sering dihadapi oleh nelayan kecil adalah mengenai penanganan pasca penangkapan. Nelayan mengharapkan ikan yang ditangkap tetap segar sampai di tangan konsumen, sehingga dapat dijual dengan harga jual yang tinggi, tetapi fakta yang ada saat ini ikan hasil tangkapan sering mengalami perubahan baik secara fisik maupun kimia yang kemudian secara bertahap mengarah pada proses pembusukan sehingga mengakibatkan harga jual ikan menjadi berkurang.Cara yang biasa dilakukan oleh nelayan tradisional adalah dengan pendinginan dan penambahan garam. Pendinginan dilakukan dengan menambahkan es batu pada palka (wadah hasil tangkap ikan), namun pemberian es batu ini akan mengurangi volume palka semakin kecil, sehingga akan berimbas pada biaya produksi yang semakin besar. Sementara pemberian garam akan mengakibatkan perubahan rasa pada ikan. Pada dasarnya prinsip dari sebuah pengawetan adalah menghambat perkembangan bakteri yang dapat memicu terjadinya pembusukan pada ikan.Dengan berbagai permasalahan tersebut, penulis akan membuat sistem refrigerator yang ringkas. Penulis juga akan menambahkan Arduino sebagai solusi untuk kendali suhu alat sehingga alat mempunyai nilai suhu sesuai standar SNI untuk pengawetan ikan yaitu 0$5^{\circ} \mathrm{C}$. Dengan solusi ini penulis berharap bisa membuat alat yang dapat mempertahankan kesegaran ikan yang dapat digunakan oleh seluruh nelayan Propinsi Lampung.

\section{TINJAUAN PUSTAKA}

\section{A. Pengawetan Ikan Dengan Menggunakan Es}

Ikan merupakan salah satu bahan pangan yang bersifat highly perishable (rentan rusak), terutama pada kondisi tropis ikan lebih cepat mengalami kemunduran mutu. Hal ini merupakan suatu fakta yang dapat ditangani dengan cara menurunkan suhu tubuh ikan agar kesegarannya tetap maksimal. Penurunan suhu tubuh ikan dapat dilakukan dengan media pendingin yang berfungsi untuk menarik atau memindahkan panas dari dalam tubuh ikan ke bahan lain sehingga suhu tubuh ikan rendah.

Ikan segar mempunyai dua pengertian, yang pertama merupakan ikan yang baru saja ditangkap, tidak disimpan atau diawetkan. Kedua, ikan yang mutunya masih baik, disimpan atau diawetkan dan mempunyai mutu yang tidak berubah serta belum mengalami kemunduran, baik secara kimia, fisika, maupun biologi walaupun sudah mengalami penyimpanan, misalnya ikan-ikan yang dibekukan [1]. Kesegaran akan bisa dicapai bila dalam penanganan ikan berlangsung dengan baik. Ikan yang masih segar berarti belum mengalami perubahanperubahan biokimiawi, mikrobiologi, maupun fisikawi yang dapat menyebabkan kerusakan berat pada daging ikan. Untuk mempertahankan mutu ikan segar, bahan baku harus secepatnya diolah. Apabila terpaksa harus menunggu proses lebih lanjut maka ikan harus disimpan dengan es atau air dingin $\left(0^{\circ} \mathrm{C}\right.$ sampai dengan $\left.5^{\circ} \mathrm{C}\right)$, saniter dan higinis [2]. Teknik penanganan ikan yang paling umum digunakan untuk menjaga kesegaran ikan adalah penggunaan suhu rendah. Selanjutnya, pada kondisi suhu rendah, pertumbuhan bakteri dan prosesproses biokimia yang ada di tubuh ikan menjadi lebih lamban. Rantai dingin (cold chain) merupakan usaha menjaga mutu ikan agar tetap segar dengan menggunakan suhu rendah $\left(0^{\circ} \mathrm{C}\right.$ atau beberapa derajat celcius di atas $0^{\circ} \mathrm{C}$ ) selama kegiatan penanganan hingga sampai ke tangan konsumen [3].

\section{B. Refrigerasi}

Refrigerasi adalah metode pengkondisian temperatur ruangan agar tetap berada di bawah temperatur lingkungan. Karena temperatur ruangan yang selalu berada di bawah temperatur lingkungan, maka ruangan akan menjadi dingin, sehingga refrigerasi dapat juga disebut dengan metode 
pendinginan. Metode pendinginan (refrigerasi) ini akan berhasil dengan menggunakan bantuan zat refrigerant. Refrigerant akan bertindak sebagai media penyerap dan pemindah panas dengan cara merubah fasanya. Refrigerant adalah suatu zat yang mudah berubah fasanya dari cair menjadi uap dan sebaliknya apabila kondisi tekanan dan temperaturnya diubah.

Suatu penggunaan yang luas dari termodinamika adalah refrigerasi yaitu perpindahan panas dari temperatur yang rendah ke temperatur yang lebih tinggi. Sistem yang menghasilkan proses refrigerasi adalah refrigerator (atau pompa panas), dan siklusnya disebut siklus refrigerasi. Siklus refrigerasi yang banyak digunakan adalah siklus kompresi uap sederhana, dimana refrigeran diuapkan, dan dikodensasikan dengan jalan mengkompresi uap tersebut. Prinsip utama mesin refrigerasi adalah untuk menurunkan temperatur agar materi atau ruangan dapat terjaga temperaturnya sesuai dengan kebutuhan dan kenyamanan yang dikehendaki.

\section{1) Siklus Refrigerasi kompresi uap}

Mesin refrigerasi dengan kompresi uap merupakan sistem yang terbanyak digunakan dalam daur refrigerasi. Prinsip dasar uap ini adalah uap ditekan kemudian diembunkan setelah itu tekanannya diturunkan agar cairan itu akan menguap kembali karena menyerap panas lingkungan. Dalam sistem kompresi diperlukan 4 komponen, yaitu kompresor, kondensor, katup ekspansi dan evaporator. Fungsi dari masing-masing alat tersebut adalah sebagai berikut:

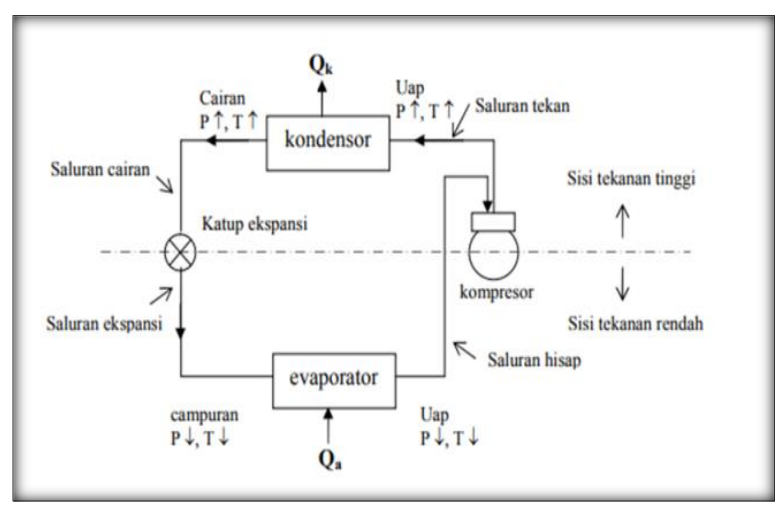

Gbr 1. Sistem Kompresi Uap Standar

\section{Arduino UNO}

Arduino Uno merupakan board mikrokontroler berbasis ATmega328. Arduino Uno emiliki 14 pin input dari output digital, dimana 6 pin input dapat digunakan sebagai output PWM dan 6 pin input analog, $16 \mathrm{MHz}$ osilator kristal, koneksi USB, jack power, ICSP header, dan tombol reset. Untuk mendukung mikrokontroler agar dapat digunakan, cukup hanya menghubungkan Board Arduino Uno ke komputer dengan menggunakan kabel USB atau adaptor DC atau baterai untuk menjalankannya.

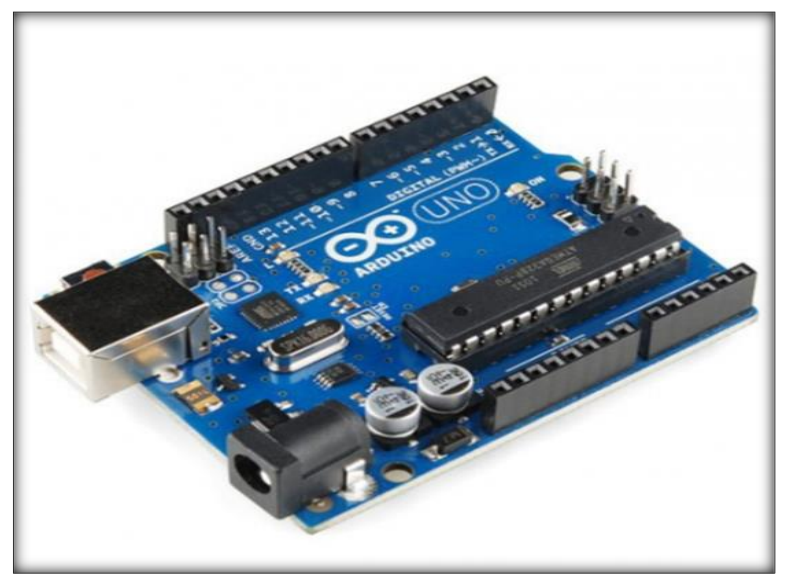

Gbr 2. Arduino UNO

\section{Sensor suhu DS18B20}

Sensor suhu DS18B20 dengan kemampuan tahan air (waterproof) bagus digunakan untuk mengukur suhu pada tempat yang lembab, atau basah. Output data dari sensor ini merupakan data digital, jadi kita tidak perlu khawatir terhadap degradasi data ketika menggunakan kabel panjang. DS18B20 menyediakan 9 bit hingga 12 bit yang dapat dikonfigurasi data. 


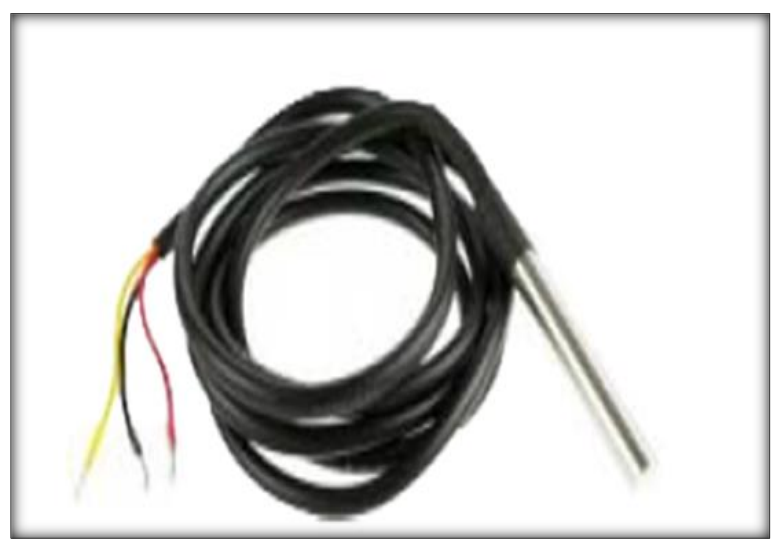

Gbr 3. Sensor Suhu DS18B20

\section{E. Photovoltaic}

Konversi energi dari cahaya matahari menjadi energi listrik dilakukan oleh komponen yang disebut sel photovoltaic (sel PV). Sel PV pada dasarnya semikonduktor dioda yang memiliki sambungan P-N. Dalam sambungan $\mathrm{P}-\mathrm{N}$ ini terbentuk tiga daerah berbeda, yaitu daerah tipe $\mathrm{P}$, tipe $\mathrm{N}$ dan daerah pengosongan (deplesi). Pada daerah tipe $\mathrm{P}$ mayoritas pembawa muatannya adalah hole, sedangkan pada daerah tipe $\mathrm{N}$ mayoritas pembawa muatan adalah elektron. Pada daerah deplesi memiliki medan listrik internal dengan arah dari $N$ ke $P$. Saat radiasi matahari mengenai sel surya maka akan terbentuk elektron dan hole. Karena pengaruh medan listrik internal pada daerah deplesi maka menyebabkan hole bergerak menuju daerah $\mathrm{P}$ dan elektron bergerak menuju daerah N. Perpindahan hole dan elektron ini menghasilkan arus yang disebut arus fotodifusi. Selain itu pada daerah deplesi dapat pula terjadi pasangan hole dan elektron karena pengaruh medan yang sama yang akan bergerak menuju ke arah mayoritasnya, sehingga menghasilkan arus.

Pada aplikasinya, tenaga listrik yang dihasilkan oleh satu modul sel surya masih cukup kecil, maka dalam pemanfaatannya beberapa modul digabungkan dengan cara hubungan seri maupun paralel yang disebut software. Bentuk software ini yang banyak diaplikasikan untuk pembangkit listrik tenaga surya (PLTS). Hirarki modul sel surya ditunjukkan pada Gbr 4 berikut:

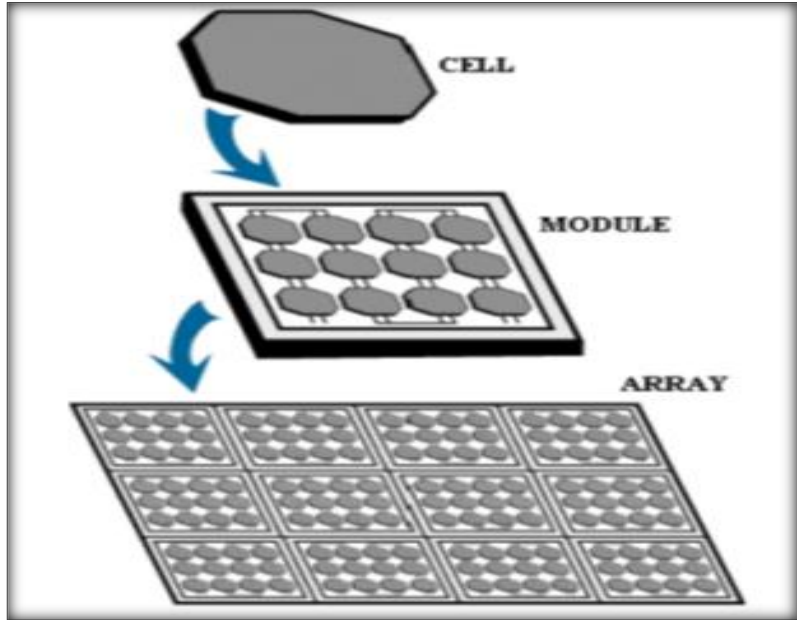

Gbr 4. Hirarki Modul Sel Surya

\section{F. Relay}

Dalam dunia elektronika, relay dikenal sebagai komponen yang dapat mengimplementasikan logika switching. Sebelum tahun 70an, relay merupakan "otak" dari rangkaian pengendali. Baru setelah itu muncul PLC yang mulai menggantikan posisi relay. Relay yang paling sederhana ialah relay elektromekanis yang memberikan pergerakan mekanis saat mendapatkan energi listrik. Secara sederhana relay elektromekanis ini didefinisikan sebagai berikut :

- Alat yang menggunakan gaya elektromagnetik untuk menutup (atau membuka) kontak saklar

- Saklar yang digerakkan (secara mekanis) oleh daya/energi listrik

\section{1) Prinsip Kerja dan Simbol}

Relay terdiri dari coil dan contact. Perhatikan Gbr.5, coil adalah gulungan kawat yang mendapat arus listrik, sedang contact adalah sejenis saklar yang pergerakannya tergantung dari ada tidaknya arus listrik di coil. Contact ada 2 jenis : Normally Open (kondisi awal sebelum diaktifkan open), dan Normally Closed (kondisi awal sebelum diaktifkan close). Secara sederhana berikut ini prinsip kerja dari relay : ketika Coil mendapat energi listrik (energized), akan timbul gaya elektromagnet yang akan menarik armature yang berpegas, dan contact akan menutup. 


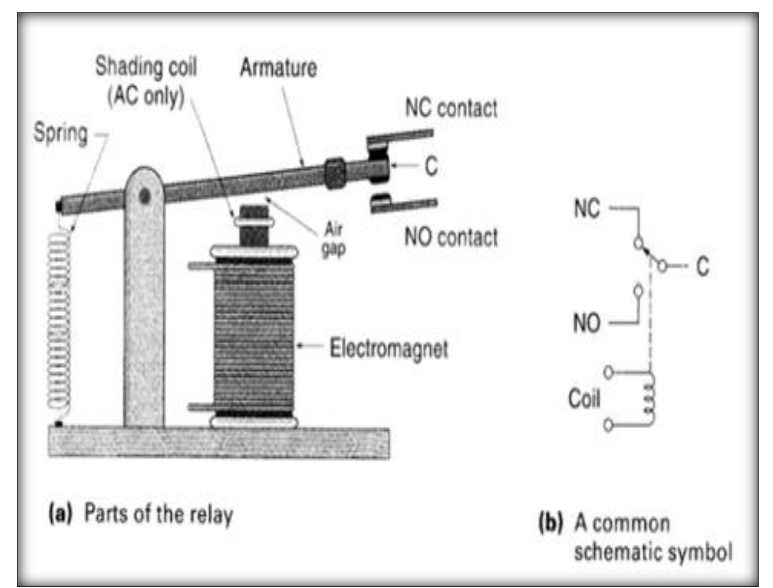

Gbr 5. Skema relay elektro mekanik

Timing relay adalah jenis relay yang khusus. Cara kerjanya ialah sebagai berikut: jika coil dari timing relay $\mathrm{ON}$, maka beberapa detik kemudian, baru contact relay akan $\mathrm{ON}$ atau OFF (sesuai jenis NO/NC contact). Simbol dari timing relay bisa dilihat pada gambar 6. Sedang latching relay ialah jenis relay digunakan untuk latching atau mempertahankan kondisi aktif input sekalipun input sebenarnya sudah mati. Cara kerjanya ialah sebagai berikut : jika latch coil diaktifkan, ia tidak akan bisa dimatikan kecuali unlatch coil diaktifkan. Simbol dari latching relay bisa dilihat pada Gbr 6 .

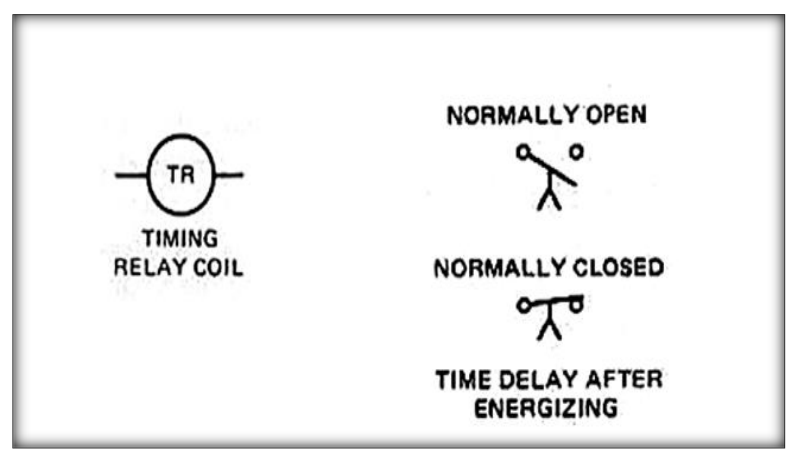

Gbr 6. Simbol coil dan contact dari timing relay

\section{METODE PENELITIAN}

Penelitian ini terdiri dari beberapa tahapan dalam pelaksanaannya, yaitu dijelaskan pada diagram alir pada Gambar 7. berikut:

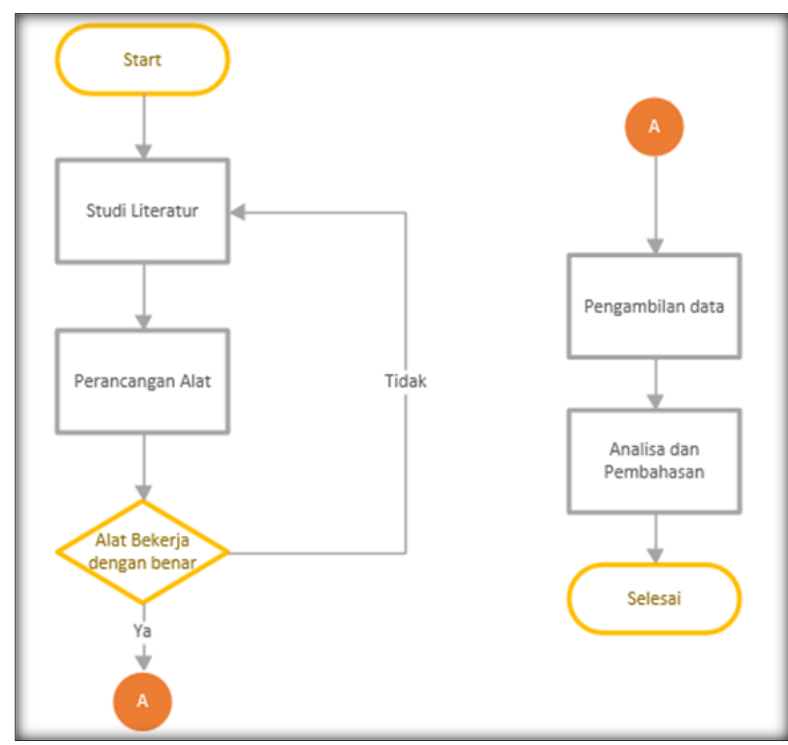

Gbr 7. Diagram Alir Penelitian

\section{A. Studi Literatur}

Dalam studi literatur dilakukan pencarian informasi atau bahan materi baik dari buku, jurnal, bahan dari internet maupun sumbersumber lain yang berkaitan dengan penelitian ini. Beberapa bahan materi tersebut diantaranya adalah: Sistem Perpipaan Refrigerator dan Sistem kendali suhu.

\section{B. Perancangan Alat}

Rangka dibangun menggunakan kayu yang berbentuk balok. Rangka terbuat dari kayu hal ini dikarenakan kayu bahan yang kuat dan tidak mudah mengalami karat. Palka/tempat pendingin ikan terbuat dari polyfoam yang dilapisi dengan plat alumunium $0,35 \mathrm{~mm}$ yang mempunyai volume total sebesar 40 liter.

\section{Pengujian alat}

Pengujian alat dilakukan untuk mengetahui kinerjanya agar didapat hasil yang baik dan memuaskan. Uji coba alat dilakukan di Laboratorium Terpadu Teknik Elektro. Uji coba meliputi melihat performa mesin pendingin ini dengan cara melihat perubahan suhu palka pada setiap detik sekali pada rentang waktu dua jam.

\section{Pengambilan Data}

Data yang diambil dari pengujian alat adalah performasi mesin pendingin. Percobaan dilakukan dengan dua perlakuan dan masing-masing percobaan dilakukan satu kali pengulangan. Data yang diambil adalah 
data Perubahan suhu palka setiap 15 detik sekali pada rentang waktu 210 menit. Selanjutnya data yang diperoleh, diolah menggunkan Microsoft Excel dan dibuat menjadi grafik yang menyajikan hubungan antara perubahan suhu terhadap perubahan waktu. Berdasarkan visualisasi grafik tersebut, kita dapat melihat waktu yang dibutuhkan untuk mendinginkan suatu muatan yang ada didalamnya.

\section{E. Analisa dan Pembahasan}

Tahapan terakhir adalah analisa dan pembahasan. Dari analisa ini akan diketahui perbandingan hasil pengujian sistem baik perbagian maupun secara keseluruhan dengan nilai yang diharapkan dari literatur yang ada.

\section{F. Penulisan Laporan}

Tahap terakhir dari penelitian ini adalah pembuatan laporan dari semua kegiatan penelitian yang telah dilakukan.

\section{HASIL DAN PEMBAHASAN}

\section{A. Blok Diagram Alir Sistem}

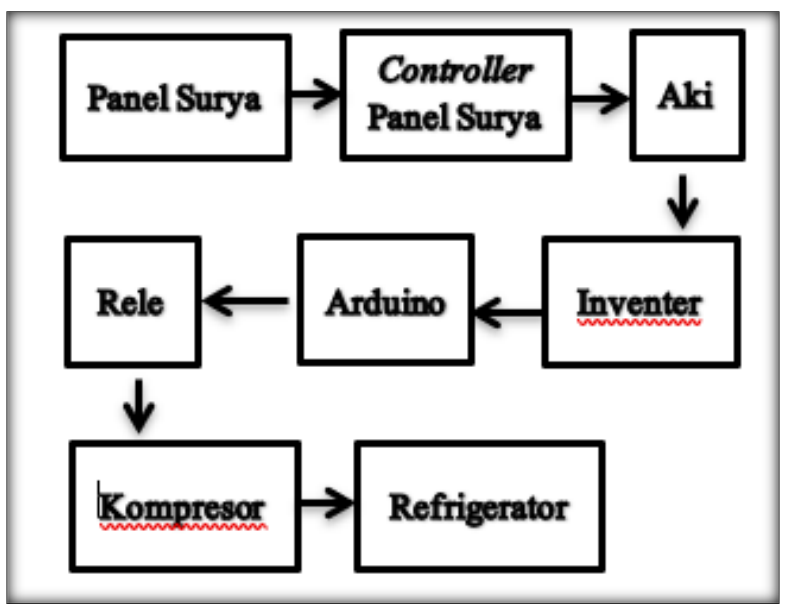

Gbr 8. Diagram blok sistem

Daya yang didapat dari panel surya diturunkan tegangannya terlebih dahulu oleh Controller panel surya sebelum masuk ke Aki. Kemudian arus aki yang masih berupa arus searah (DC) diubah menjadi arus bolakbalik (AC) oleh inverter, hal ini karena arus yang dibutuhkan oleh kompresor adalah arus bolak-balik. Kemudian Arduino akan mengatur catu daya kompresor dari inverter, apabila sensor suhu membaca nilai suhu refrigerator diatas $5^{\circ} \mathrm{C}$ maka relay akan active dan kompresor hidup. Dan apabila suhu refrigerator sudah terbaca dibawah $0^{\circ} \mathrm{C}$ relay akan inactive dan mematikan kompresor.

Rangka terdiri dari dua bagian, yaitu rangka mesin dan rangka pendingin. Rangka mesin dibangun menggunakan kayu yang berbentuk balok dengan panjang $85 \mathrm{~cm}$ lebar $50 \mathrm{~cm}$ dan tinggi $70 \mathrm{~cm}$. Rangka terbuat dari kayu hal ini dikarenakan kayu bahan yang kuat dan tidak mudah mengalami karat. Rangka pendingin ikan terbuat dari polyfoam yang dilapisi dengan plat alumunium $0,5 \mathrm{~mm}$ yang mempunyai volume total sebesar 40 liter dengan dimensi panjang $68 \mathrm{~cm}$, lebar $40 \mathrm{~cm}$ dan tinggi $45 \mathrm{~cm}$. Penggunaan polyfoam dan alumunium dikarenakan bahan polyfoam mempunyai daya tahan terhadap penangaruh panas dari luar (insulasi). Tampilan luar refrigerator dapat dilihat pada Gbr 9.

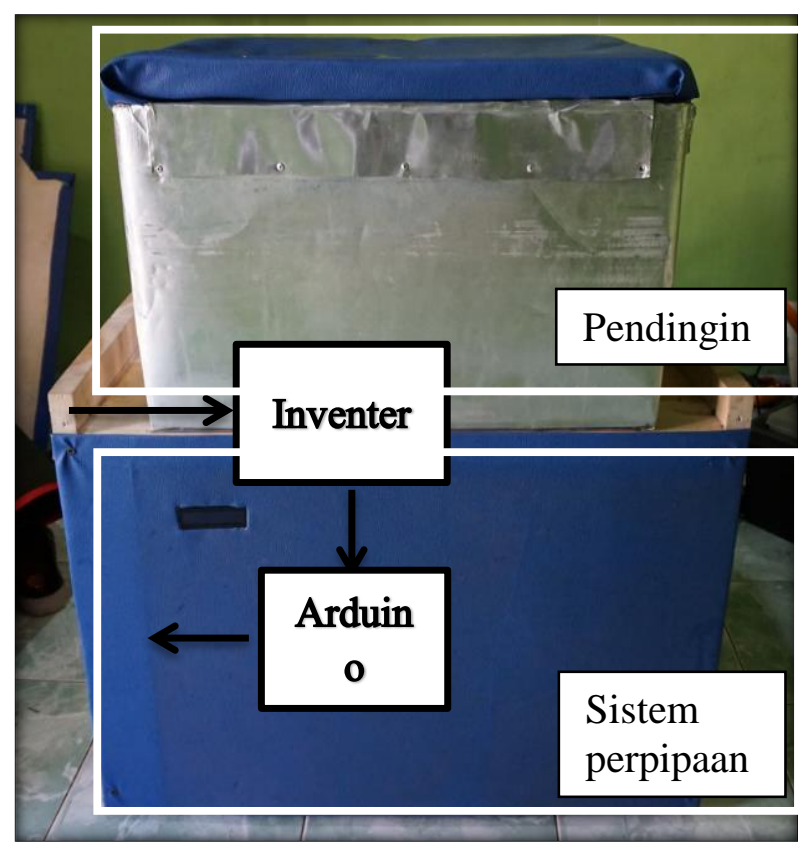

Gbr 9. Tampak Luar Refrigerator

\section{B. Pengujian Refrigerator di Bagan Nelayan}

Lokasi Pengujian alat adalah desa Pulau Pasaran Kecamatan Teluk Betung, Bandar Lampung. Pengujian di lakukan di bagan tancap dengan ukuran $5 \times 5$ meter. Pengujian dilakukan dari pukul 20.30 WIB sampai dengan 23.30 WIB. Selama itu nelayan 
melakukan satu kali pengangkatan hasil tangkap. Parameter yang diukur adalah suhu dari refrigerator. Pengukuran dilakukan setiap 15 detik dan dicatat dalam Microsoft Excel. Data yang diperoleh adalah sebagai berikut

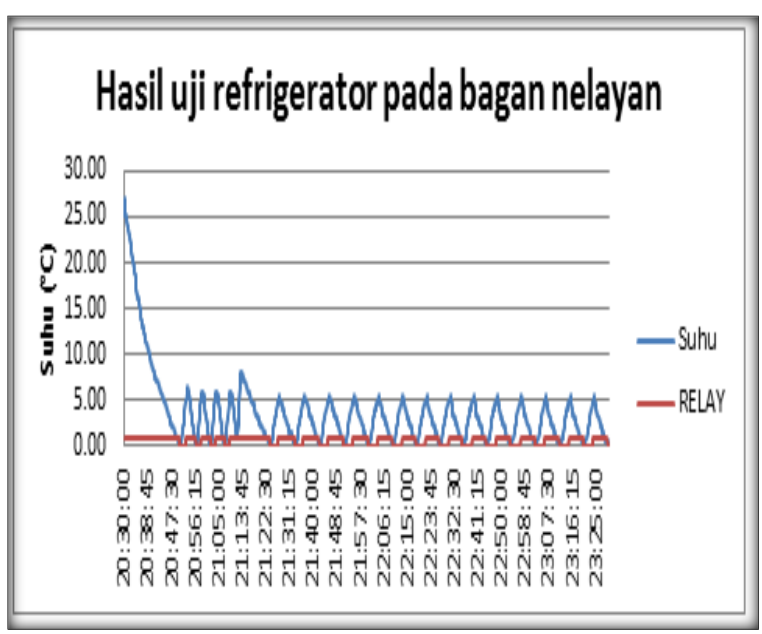

Gbr 10. Grafik Hasil uji refrigerator pada bagan nelayan

Refrigerator mencapai suhu $0^{\circ}$ pada menit ke 00:20:45 yaitu pada pukul 20:50:45 WIB dan pada saat itu juga relay inactive untuk mematikan refrigerator. Pada keadaan kosong sebelum diisi ikan rata refrigerator membutuhkan waktu 3 menit 30 detik untuk mencapai suhu dari $5^{\circ} \mathrm{C}$ ke $0^{\circ} \mathrm{C}$. Pada pukul 21:13:15 WIB suhu naik ke $8^{\circ} \mathrm{C}$. Hal ini dikarenakan refrigerator dibuka untuk dimasukan ikan didalamya. Setelah itu suhu refrigerator kembali ke menuju $0^{\circ} \mathrm{C}$.

\section{KESIMPULAN}

Berdasarkan analisa pada kondisi tanpa sistem kendali dan beban kosong refrigerator mencapai suhu $0^{\circ} \mathrm{C}$ dalam waktu 17 menit dan mencapai suhu maksimal sebesar $-13^{\circ} \mathrm{C}$ dalam waktu 1 jam 20 menit. Pada kondisi tanpa sistem kendali dan beban penuh refrigerator mencapai suhu $0^{\circ} \mathrm{C}$ dalam waktu 49 menit 30 detik dan mencapai suhu maksimal sebesar $-5^{\circ} \mathrm{C}$ dalam waktu 3 jam 13 menit 30 detik. Dengan sistem kendali refrigerator dapat mempertahankan range suhu yang diinginkan yaitu $0-5^{\circ} \mathrm{C}$, dengan waktu rata-rata dari suhu $5^{\circ} \mathrm{C}$ ke $0^{\circ} \mathrm{C}$ adalah 3 menit 30 detik, dan dari suhu $0^{\circ} \mathrm{C}$ ke $5^{\circ} \mathrm{C}$ adalah 1 menit 30 detik.

\section{REFERENSI}

[1] Wibowo, S. dan Yunizal, 1998. Penanganan ikan segar. Instalasi Perikanan Laut Slipi. Jakarta.

[2] Anonim.2006. SNI 01-2729.1-2006 Tentang Spesifikasi Ikan Segar.

[3] Santoso Hendi.2013. Alat Pendingin Ikan Portabel Menggunakan Energi Listrik Tenaga Surya. Jawa Barat.

[4] K, Abdul. 2014. From Zero to Hero ARDUINO. Yogyakarta

[5] Datasheet Sensor Suhu DS18B20

[6] Wulandari, Handini. 2008. Peforma Sel Surya. Depok: Universitas Indonesia

[7] Kilian, Christopher T. 1996. Modern Control Technology. http://www.goodreads.com/author/sho w/1139124.Christopher_T_Kilian 